\title{
Dissatisfaction with traditional birth attendants in rural Tanzania
}

\author{
Godfrey Mbaruku ${ }^{\text {a,f }}$, Beverly Msambichaka ${ }^{\text {a }}$, Sandro Galea ${ }^{\text {b,c,d }}$, Peter C. Rockers ${ }^{\text {b }}$, Margaret E. Kruk ${ }^{\text {e,f,* }}$ \\ a Ifakara Health Institute, Mikocheni, Dar Es Salaam, Tanzania \\ b University of Michigan School of Public Health, Department of Epidemiology, Ann Arbor, Michigan, USA \\ ${ }^{c}$ University of Michigan Survey Research Center, Institute for Social Research, Ann Arbor, Michigan, USA \\ ' University of Michigan, Center for Global Health, Ann Arbor, Michigan, USA \\ e University of Michigan School of Public Health, Department of Health Management and Policy, Ann Arbor, Michigan, USA \\ ${ }^{f}$ Averting Maternal Death and Disability Program, Heilbrunn Department of Population E' Family Health, Mailman School of Public Health, Columbia University, New York, USA
}

\section{A R T I C L E I N F O}

\section{Article history:}

Received 11 February 2009

Received in revised form 6 April 2009

Accepted 8 May 2009

\section{Keywords:}

Home delivery

Maternal health

Patient satisfaction

Skilled birth attendance

Tanzania

Traditional birth attendants

\begin{abstract}
A B S T R A C T
Objective: To assess women's satisfaction with traditional birth attendants (TBAs) in rural Tanzania. Method: A population-representative sample of households in Kasulu district was used to collect data on demographics, childbirth history, and perception of TBAs and doctors/nurses from women who had recently had a child and from their partners. Results: Two-thirds of women who gave birth in a health facility reported being very satisfied with the experience, compared with $21.2 \%$ of women who delivered at home with TBAs. A sizeable proportion of women felt that TBAs had poor medical skills (23.1\%), while only $0.3 \%$ of women felt the same about doctors' and nurses' skills. Of women who delivered with a TBA, 16.0\% reported that TBAs had poor medical skills whereas $0.5 \%$ stated the same for doctors and nurses. Conclusion: Although many women delivered at home in this rural study district, women and their partners reported higher confidence in doctors and nurses than in TBAs. Policymakers and program managers should not assume that women prefer TBAs to trained professionals for delivery but should consider system barriers to facility delivery in interventions aimed at reducing maternal mortality.
\end{abstract}

(c) 2009 International Federation of Gynecology and Obstetrics. Published by Elsevier Ireland Ltd. All rights reserved.

\section{Introduction}

More than half a million women die because of pregnancy every year and approximately $99 \%$ of these women perish in the poorest of nations [1]. However, the issue of maternal mortality has only recently begun to be addressed internationally, most notably through inclusion of maternal health as a Millennium Development Goal [1,2]. Interventions needed to reduce maternal mortality by nearly $75 \%$ already exist, and the biggest challenge facing policy makers in low-income countries is to enhance access to skilled birth attendants and emergency obstetric care [3,4]. At the moment, formal health service utilization for essential maternal health services is inadequate, with very low coverage among the poor due to a host of barriers ranging from distance and cost of care, to concerns about quality of care and, in some countries, cultural barriers [5-9].

Tanzania has a high maternal mortality ratio ( 578 deaths per 100000 live births) [10]. Widespread deployment of health professionals with midwifery skills (skilled attendants) and emergency back support is critical to the reduction of maternal mortality [11]. However, Tanzania is burdened by a serious deficit in human resources for health. The

\footnotetext{
* Corresponding author. Department of Health Management and Policy, University of Michigan School of Public Health, 109 Observatory Road, M3166, Ann Arbor, MI 48109-2029, USA. Tel.: +1734615 3633; fax: +1734 7644338 .

E-mail address: mkruk@umich.edu (M.E. Kruk).
}

shortage of human resources is across all cadres relevant to labor and delivery: for every nurse and midwife in Tanzania there is a population of nearly 4000 , and for every specialist in obstetrics and gynecology there is a population of nearly 400000 [12].

Traditional birth attendants (TBAs) are community-based maternal care providers, some of whom receive short training in childbirth and postnatal care [13]. TBAs attend over half (55\%) of all home deliveries in Tanzania [10]. Most TBAs work independently of the health system, and evidence from Africa suggests that TBAs are unable to cope effectively with either severe complications or pending, potentially life-threatening conditions [14]. In fact, a recent meta-analysis of maternal mortality outcomes following TBA training concluded that TBA outcomes were substantially worse than outcomes for other trained providers [15]. There is, however, widespread TBA utilization in many communities throughout Africa, which some research suggests is because women are more satisfied with TBA care than with the care provided by other healthcare workers [16]. However, data on satisfaction with health providers are limited, and the extent to which women prefer TBAs over doctors and nurses for delivery care is not well understood.

The aim of the present study was to assess women's satisfaction with home delivery attended by TBAs compared with facility delivery in dispensaries, health centers, and hospitals in rural western Tanzania; and to assess the confidence in doctors and nurses compared with TBAs reported by the women and their partners. 


\section{Materials and methods}

Kasulu District is located along Tanzania's western border, 1370 kilometers from Dar es Salaam. The district's 630000 inhabitants [17] live in primarily rural conditions and the majority engage in subsistence farming. Kasulu has 48 functioning government dispensaries that account for a substantial proportion of healthcare service provision. In addition, there are 22 other health facilities in the district, including one government district hospital where obstetric complications are treated.

This study employed a 3-stage representative rural cluster sample of households from Kasulu District, omitting Kasulu Town. Fifty villages were chosen in the first stage, with probability proportional to size, based on the 2002 Tanzania census. One sub-village (approximately 100 households) within each village was then randomly selected, and the leader of that sub-village provided a list of households from which 35 were selected through systematic random sampling. Inclusion criteria limited participants to women over the age of 18 years with a delivery within the 5 years prior to recruitment and their current spouse. The National Institute for Medical Research in Tanzania, as well as the Institutional Review Board at the University of Michigan, provided human subjects research approval for the study. Written consent was obtained from all respondents.

Questionnaires and consent documents were developed in English and translated into Swahili and then back translated to assure accuracy. Questionnaires collected information about household composition, characteristics and assets (indicators of socioeconomic status/wealth), childbirth history, knowledge and perception of the local healthcare system, quality of care, and barriers to healthcare utilization. The men's questionnaire was briefer, consisting of questions about local health facilities, use of the health system for injury, and perceptions of the quality of care. Men were interviewed separately from their wives. Questionnaire administration was conducted by 2 team members trained in fluent Kiswahili and English and took place between June and mid-July 2007.

Facility delivery was defined as giving birth in a government or mission dispensary, health center, or hospital. Home deliveries included those that occurred either at the participant's home or the home of a friend or TBA. Information about who attended a home delivery was collected. Women who described their birth as occurring "on the way" to a facility were excluded from the analyses. Women who delivered at home were asked to select one or more reasons for not delivering in a health facility.

Satisfaction with delivery (for women only) was based on the question "Overall, how satisfied were you with the care you received for your delivery?" for facility deliveries, and "Overall, how satisfied were you with your decision to deliver at home?" for home deliveries. The variable was dichotomized as "Very satisfied" versus "less than very satisfied." Variables related to perceptions of provider skill and effort were asked of both women and their spouses and were dichotomized into "poor" and "better than poor," where "poor" corresponds to a response of "Strongly disagree" to the statements: "In general, I believe that (government doctors and nurses)/(traditional birth attendants) (have good medical skills)/(make an effort to provide good quality care)." These cut-off points were chosen to minimize bias caused by social desirability (whereby women feel social pressure not to be critical) and were supported by the raw variables' univariate distributions.

Each woman was also asked how much she paid for various components of her delivery including doctor's/nurse's fees, drugs, nonmedical supplies, medical tests, transport, maternity waiting home, and other expenses. The reported figures were then summed to create the "Total cost of delivery" variable.

Univariate statistics were calculated for demographic variables as well as for select healthcare-related variables. Bivariate associations with assistance with delivery were calculated for several variables of interest. All statistical analyses were adjusted for the survey's cluster design and were carried out with SAS-Callable SUDAAN version 9.0.3 (Research Triangle Institute, NC, USA).

\section{Results}

Of the 1322 eligible respondents recruited for the study, 1205 (91.1\%) women completed questionnaires. One respondent did not provide information on her location of delivery and as a result was excluded from this analysis. Of all women surveyed, $76.1 \%$ lived in a village with a functioning health facility and $86.4 \%$ of women had 2 or more living children at the time of the interview. Only $36.6 \%$ of women in the study gave birth to their last child at a facility; $37.0 \%$ gave birth at home with a TBA; $23.7 \%$ gave birth at home without a traditional birth attendant. There were significant differences in demographic characteristics among the 3 groups for age older than 35 years $(P=0.05)$ and number of living children $(P<0.01)$ (Table 1$)$. Education and ownership of goods were not found to be significantly different among the groups. Among home delivery respondents, reasons given for not delivering in a health facility by more than $10 \%$ of female respondents were: lack of transport (44.9\%), advice of husband or TBA (19.5\%), and inadequate medicines (14.4\%). The average cost of delivery among women who gave birth in a facility was $5796 \mathrm{TZS}(95 \% \mathrm{CI}, 4537-7055)$; 1480 TZS (95\% CI, 1296-1665) among women who gave birth at home with a traditional birth attendant; and 366 TZS (95\% CI, 255-476) among women who gave birth at home without a traditional birth attendant.

Two-thirds (66.7\%) of women who gave birth in a facility were very satisfied with their experience (Table 2). In contrast, $21.2 \%$ of women who gave birth at home with a traditional birth attendant were very satisfied and $25.2 \%$ of women who gave birth at home without a traditional birth attendant were very satisfied. An overall test of significance showed that this satisfaction variable was significantly associated with type of assistance with delivery $(P<0.01)$. Unadjusted associations between assistance with delivery and perceptions of provider skills and effort are also shown in Table 2. Among the entire female population, only $0.3 \%$ felt that doctors/nurses had poor skills, while $23.1 \%$ felt that TBAs had poor skills $(P<0.01)$. Similarly, $5.6 \%$ of women felt that doctors/ nurses made a poor effort to provide good quality care compared with

Table 1

Sociodemographic characteristics and cost of delivery for a population-based sample of women from Kasulu District, Western Tanzania, 2007.

\begin{tabular}{|c|c|c|c|c|c|}
\hline \multirow[t]{2}{*}{ Characteristics } & \multirow{2}{*}{$\begin{array}{l}\text { Total } \\
(\mathrm{n}=1172)\end{array}$} & \multicolumn{3}{|c|}{ Assistance with delivery } & \multirow[t]{2}{*}{$P$ value $^{\mathrm{b}}$} \\
\hline & & Facility $(n=441)$ & Home with TBA $(n=446)$ & Home $\mathrm{w} / \mathrm{o}$ TBA $(\mathrm{n}=285)$ & \\
\hline Age $>35, y$ & $335(28.6)$ & $115(26.1)$ & $119(26.7)$ & $101(35.4)$ & 0.05 \\
\hline No schooling & $325(27.7)$ & $111(25.2)$ & $131(29.4)$ & $83(29.1)$ & 0.50 \\
\hline Number of living children & $4.2 \pm 0.1$ & $3.8 \pm 0.1$ & $4.3 \pm 0.2$ & $4.7 \pm 0.2$ & $<0.01$ \\
\hline Poorest wealth quintile & $217(18.5)$ & $82(18.6)$ & $89(20.0)$ & $46(16.1)$ & 0.34 \\
\hline Owns phone & $85(7.3)$ & $40(9.1)$ & $25(5.6)$ & $20(7.0)$ & 0.26 \\
\hline Eats more than 2 meals/day & $129(11.0)$ & $54(12.2)$ & $53(11.9)$ & $22(7.7)$ & 0.07 \\
\hline Cost of delivery, $\mathrm{TZS}^{\mathrm{c}}$ & $2868.8 \pm 257.3$ & $5796.1 \pm 626.7$ & $1480.4 \pm 91.8$ & $365.8 \pm 55.1$ & $<0.01$ \\
\hline
\end{tabular}

a Values are given as number (percentage) or mean \pm standard error unless otherwise indicated.

b P value expresses the likelihood of a difference among the 3 groups (facility, home with TBA, and home without TBA).

c Total cost of all aspects of delivery (including transport, supplies, provider fees, medicines, etc) in Tanzanian Shillings (TZS) $(1 \mathrm{US} \$$ bopsp $=1245 \mathrm{TZS}$ ). 
Table 2

Satisfaction and perceptions of provider skills and effort for a population-based sample from Kasulu District, Western Tanzania, 2007. ${ }^{a}$

\begin{tabular}{|c|c|c|c|c|c|}
\hline & \multirow[t]{2}{*}{ Total } & \multicolumn{3}{|c|}{ Place of delivery } & \multirow[t]{2}{*}{$P$ value } \\
\hline & & Facility & $\begin{array}{l}\text { Home } \\
\text { with TBA }\end{array}$ & $\begin{array}{l}\text { Home } \\
\text { w/o TBA }\end{array}$ & \\
\hline \multicolumn{6}{|l|}{ Women } \\
\hline \multicolumn{6}{|l|}{ Satisfaction with delivery ${ }^{c}$} \\
\hline Fairly satisfied & 29.8 & 24.4 & 39.9 & 22.3 & $<0.01$ \\
\hline Very satisfied & 39.3 & 66.7 & 21.2 & 25.1 & $<0.01$ \\
\hline Either fairly or very satisfied & 69.0 & 91.1 & 61.0 & 47.3 & $<0.01$ \\
\hline \multicolumn{6}{|l|}{ Perception of poor provider skill ${ }^{\mathrm{d}}$} \\
\hline Doctor/nurse & 0.3 & 0.2 & 0.5 & 0.4 & 0.83 \\
\hline Traditional birth attendant & 23.1 & 28.4 & 16.0 & 26.7 & $<0.01$ \\
\hline \multicolumn{6}{|c|}{ Perception of poor provider effort ${ }^{\mathrm{e}}$} \\
\hline Doctor/nurse & 5.6 & 4.6 & 5.2 & 7.7 & 0.21 \\
\hline Traditional birth attendant & 18.1 & 24.6 & 10.8 & 19.8 & $<0.01$ \\
\hline \multicolumn{6}{|l|}{ Men } \\
\hline \multicolumn{6}{|l|}{ Perception of poor provider skill ${ }^{d}$} \\
\hline Doctor/nurse & 1.3 & 1.3 & 1.3 & 1.5 & 0.97 \\
\hline Traditional birth attendant & 26.5 & 29.3 & 20.7 & 31.5 & 0.02 \\
\hline \multicolumn{6}{|c|}{ Perception of poor provider effort $\mathrm{e}^{\mathrm{e}}$} \\
\hline Doctor/nurse & 4.1 & 4.4 & 3.7 & 4.1 & 0.86 \\
\hline Traditional birth attendant & 20.4 & 23.9 & 15.4 & 22.9 & 0.02 \\
\hline
\end{tabular}

a Values are given as percentage.

b $P$ value expresses the likelihood of a difference among the 3 groups (facility, home with TBA, and home without TBA). Separate $\chi^{2}$ tests showed significant differences $(P<0.01)$ in perceptions of both skill and effort comparing doctors/nurses to TBAs for all "Assistance with delivery" groups, for both women and men.

c Facility deliveries correspond to the question: "Overall, how satisfied were you with the care you received for your delivery?" Home deliveries correspond to the question: "Overall, how satisfied were you with your decision to deliver at home?"

d Percentage responding "Strongly disagree" to the statement: "In general, I believe that (government doctors and nurses)/(traditional birth attendants) have good medical skills."

e Percentage responding "Strongly disagree" to the statement: "In general, I believe that (government doctors and nurses)/(traditional birth attendants) make an effort to provide good quality care."

$18.1 \%$ of women who felt that this was true for traditional birth attendants $(P<0.01)$. Differences in perception of skill and effort were also significant among all men. Large and significant differences remained after stratifying the population by the assistance with delivery variable, for all categories of delivery assistance. However, women who delivered at home with a TBA and their husbands tended to rate TBAs skills and efforts higher than women who delivered in a health facility or at home without a TBA.

\section{Discussion}

High rates of home delivery were found in a sample of women in rural Kasulu district in Tanzania. Women who delivered at home were less satisfied with their delivery experience than women who delivered in a health facility. Among women who delivered with a TBA, only 1 in 5 reported being "very satisfied" versus two-thirds of women who reported the same for a facility delivery. Overall satisfaction was lowest among women who delivered at home without a TBA. Regardless of where women delivered, they gave lower ratings to the medical skills of TBAs than they did for the medical skills of doctors and nurses. Less than $1 \%$ of women felt that doctors and nurses had poor medical skills, whereas one-quarter reported that TBAs had poor skills. Although women who delivered with a TBA had the lowest rate of negative opinions about TBAs, their ratings of doctor and nurse skills were substantially better.

There was greater heterogeneity of opinion about the skills and effort of TBAs than doctors and nurses, with almost all women expressing positive perceptions of physicians and nurses. Spouses' opinions about skills and effort were similar to the women's opinions in all 3 groups. This suggests that there is substantial intra-household agreement about the value of skilled birth attendance in this population. Combined, these findings challenge the notion that women (and/or their families) are strongly attached to TBAs and prefer their services to those obtained in health facilities, or that women do not distinguish between the medical skills of skilled and traditional birth attendants [18,19].

Other authors have reported that women may not be entirely satisfied with a TBA-attended delivery. For example, although only $42 \%$ of women delivered in a facility in rural Zambia, $75 \%$ expressed preference for facility delivery versus home delivery [20]. The constraints to facility delivery reported in that study included unavailability of transport and lack of preparation for the onset of labor [20]. A small study of TBAs and their clients in rural Nigeria found that only half of all women who received TBA care would recommend it to others [16].

The present study's findings of a positive perception of the health system may be influenced by a previous effort in Kigoma region (of which Kasulu District is part) to reduce maternal mortality through facility-based quality improvements that succeeded in reducing hospital-based maternal mortality from 933 to 186 per 100000 live births [21]. The successful results may have led the population to regard the health system as being superior to homes for deliveries and enhanced trust in formal health care. Resulting awareness about the capacity of skilled birth attendants cut across all levels of society, and perhaps explains why the present study, unlike several others [16,22], did not find an association between education or wealth in individual preference. Despite this, there are still barriers that limit delivery in health facilities in this area. We have demonstrated in previous work that quality and costs of formal health services play an important role in reducing demand for facility delivery in this population [23,24].

Women may also be persuaded to deliver at home by important social preferences and pressures and by diminishing concern about the risks of childbirth with increased parity [25]. Across Africa, TBAs have built strong roots that are both socially and culturally based [22]. Researchers have documented that women value TBAs' social skills, patience, and respect, and the additional services that TBAs provide such as cooking, cleaning, and washing [11]. Other studies examining sociocultural reasons for continued high rates of home delivery point to factors such as the relative privacy afforded by home delivery, higher social status gained from not needing birth assistance, and fear of surgical delivery $[25,26]$.

As with all surveys, the present study has several limitations. Communities in Tanzania are aware of recommended health-seeking behaviors and responses may thus be subject to social desirability bias. An attempt to control this was made by restricting analysis to women with the most extreme views (e.g., strongly disagree that TBAs have good medical skills) rather than the middle category (disagree), on the assumption that women would be less likely to dramatically misrepresent their views. Women's recall may worsen with time, particularly for deliveries several years previously. However, $84 \%$ of the women in the analysis delivered their last child within the previous 2 years, thus reducing recall error. Furthermore, given the importance of childbirth, women may be expected to remember their satisfaction with their delivery experience and perspectives on health providers. Finally, no data were collected regarding reasons for levels of satisfaction with delivery care. Qualitative data methods could have afforded important insights.

The present study suggests that it is important not to make assumptions regarding women's preferences for delivery care based only on past behavior, as this may be constrained by barriers to health system use. There is experience to suggest that supply-side improvements can play a powerful role in bringing women to the health system. Researchers in Kuwait and Oman found that TBA-attended deliveries decreased without any specific planning and policies, simply because of increased availability and quality of health facilities which over time increased confidence in the healthcare system [27]. In these settings, the provision of a viable alternative to TBA care was enough to motivate women to deliver in a health facility. In more resource-constrained 
countries, however, interim interventions may be required to reduce maternal mortality. A community intervention package that teaches women, as well as their husbands and TBAs, about pregnancy danger signs and life-threatening complications may help to further develop preference for a competent pair of hands during delivery. Providing transportation to more distant high-quality health facilities may help overcome physical barriers to facility delivery. In the interim, the Tanzanian government is encouraging TBAs to act as general health promoters in their communities while a newly commissioned cadre of skilled health workers are trained and the health system is improved (personal communication, March 29, 2009). If supported through careful evaluation, such programs may accelerate progress toward the goal of universal skilled birth attendance in rural Tanzania and in other countries struggling with high maternal mortality.

\section{References}

[1] Ronsmans C, Graham WJ. Maternal mortality: who, when, where, and why. Lancet 2006;368(9542):1189-200

[2] Bullough C, Meda N, Makowiecka K, Ronsmans C, Achadi EL, Hussein J. Curren strategies for the reduction of maternal mortality. BJOG 2005;112(9):1180-8.

[3] ten Hoope-Bender P, Liljestrand J, MacDonagh S. Human resources and access to maternal health care. Int J Gynecol Obstet 2006;94(3):226-33.

[4] Masanja H, de Savigny D, Smithson P, Schellenberg J, John T, Mbuya C, et al. Child survival gains in Tanzania: analysis of data from demographic and health surveys. Lancet 2008;371(9620):1276-83.

[5] Walraven G, Telfer M, Rowley J, Ronsmans C. Maternal mortality in rural Gambia: levels, causes and contributing factors. Bull World Health Organ 2000;78(5):603-13.

[6] Gage AJ, Guirlene Calixte M. Effects of the physical accessibility of maternal health services on their use in rural Haiti. Popul Stud (Camb) 2006;60(3):271-88.

[7] Noor AM, Zurovac D, Hay SI, Ochola SA, Snow RW. Defining equity in physical access to clinical services using geographical information systems as part of malaria planning and monitoring in Kenya. Trop Med Int Health 2003;8(10):917-26.

[8] Osubor KM, Fatusi AO, Chiwuzie JC. Maternal health-seeking behavior and associated factors in a rural Nigerian community. Matern Child Health J 2006;10(2):159-69.

[9] Witter S, Arhinful DK, Kusi A, Zakariah-Akoto S. The experience of Ghana in implementing a user fee exemption policy to provide free delivery care. Reprod Health Matters 2007;15(30):61-71.
[10] National Bureau of Statistics (NBS) [Tanzania] and ORC Macro. Tanzania Demographic and Health Survey 2004-05. Dar es Salaam, Tanzania: National Bureau of Statistics and ORC Macro; 2005.

[11] Koblinsky M, Matthews Z, Hussein J, Mavalankar D, Mridha MK, Anwar I, et al. Going to scale with professional skilled care. Lancet 2006;368(9544):1377-86.

[12] Tanzania Service Availability Mapping 2005-2006. Dar es Salaam: Tanzania Ministry of Health and Social Welfare; 2006.

[13] Hussein AK, Mpembeni R. Recognition of high risk pregnancies and referral practices among traditional birth attendants in Mkuranga District, Coast Region, Tanzania. Afr J Reprod Health 2005;9(1):113-22.

[14] World Health Organization. World Health Report 2005 - Make Every Mother and Child Count. Geneva: World Health Organization; 2005.

[15] Sibley L, Ann Sipe T. What can a meta-analysis tell us about traditional birth attendant training and pregnancy outcomes? Midwifery 2004;20(1):51-60.

[16] Abioye-Kuteyi EA, Elias SO, Familusi AF, Fakunle A, Akinfolayan K. The role of traditional birth attendants in Atakumosa, Nigeria.J R Soc Health 2001;121(2):119-24.

[17] National Bureau of Statistics. 2002 Tanzania Census. Dar es Salaam, United Republic of Tanzania: National Bureau of Statistics; 2008.

[18] Nyanzi S, Manneh H, Walraven G. Traditional birth attendants in rural Gambia: beyond health to social cohesion. Afr J Reprod Health 2007;11(1):43-56.

[19] Parkhurst JO, Rahman SA, Ssengooba F. Overcoming access barriers for facilitybased delivery in low-income settings: insights from Bangladesh and Uganda. J Health Popul Nutr 2006;24(4):438-45.

[20] van den Boogaard J, Arntzen B, Chilwana J, Liyungu M, Mantingh A, Stekelenburg J. Skilled or traditional birth attendant? Choices of communities in Lukulu District, rural Zambia. World Health Popul 2008;10:34-43.

[21] Mbaruku G, Bergstrom S. Reducing maternal mortality in Kigoma, Tanzania. Health Policy Plan 1995;10(1):71-8.

[22] Mrisho M, Schellenberg JA, Mushi AK, Obrist B, Mshinda H, Tanner M, et al. Factors affecting home delivery in rural Tanzania. Trop Med Int Health 2007;12(7):862-72.

[23] Rockers PC, Wilson ML, Mbaruku G, Kruk ME. Source of Antenatal Care Influences Facility Delivery in Rural Tanzania: A Population-Based Study. Matern Child Health J 2008 Sep 23 [Electronic publication ahead of print].

[24] Kruk ME, Mbaruku G, Rockers PC, Galea S. User fee exemptions are not enough: out-of-pocket payments for 'free' delivery services in rural Tanzania. Trop Med Int Health 2008;13(12):1442-51.

[25] Bazzano AN, Kirkwood B, Tawiah-Agyemang C, Owusu-Agyei S, Adongo P. Social costs of skilled attendance at birth in rural Ghana. Int J Gynecol Obstet 2008;102(1):91-4.

[26] d'Oliveira AF, Diniz SG, Schraiber LB. Violence against women in health-care institutions: an emerging problem. Lancet 2002;359(9318):1681-5.

[27] Kamal IT. The traditional birth attendant: a reality and a challenge. Int J Gynecol Obstet 1998;63(Suppl 1):S43-52. 